\section{Violência nos relacionamentos afetivo-sexuais entre adolescentes de Porto Alegre, Rio Grande do Sul, Brasil: busca de ajuda e rede de apoio}

\author{
Violence in affective and sexual relationships \\ among adolescents in Porto Alegre, Rio Grande \\ do Sul State, Brazil: search for help and support \\ networks
}

\section{Violencia en las relaciones afectivo-sexuales entre adolescentes de Porto Alegre, Rio Grande do Sul, Brasil: búsqueda de ayuda y red de apoyo}

.

\section{Abstract}

This study aimed to analyze the support network reported by adolescents dealing with violent situations in affective and sexual relationships. A quantitative approach was used for the epidemiological component and a qualitative approach for the data from interviews and focus groups. The sample consisted of 283 adolescents from 15 to 19 years of age who were sophomores at public and private high schools in Porto Alegre, Rio Grande do Sul State, Brazil. The quantitative data were analyzed by description of frequencies and analysis of associations between variables. For the qualitative data, thematic content analysis was used. The results showed that only 5\% of the adolescents sought help for problems resulting from violence, and when they did so, they mainly turned to friends and family. Few adolescents cited healthcare professionals as a source of support. The study highlights the need to inquire into the implications for the healthcare system in the prevention of violence and health promotion for adolescents, aimed at the adoption of healthy relationships.

Violence Against Women; Adolescent Health; Primary Prevention; Health Promotion
Joannie dos Santos Fachinelli Soares 1 Marta Julia Marques Lopes 1 Kathie Njaine 2

\section{Resumo}

Buscou-se analisar a rede de apoio referida pelos adolescentes no enfrentamento das situações de violência nas relações afetivo-sexuais. Utilizouse abordagem quantitativa, para o inquérito epidemiológico, e qualitativa, para os dados das entrevistas e grupos focais. A amostra foi composta por 283 adolescentes de 15 a 19 anos de idade, estudantes do segundo ano do Ensino Médio de escolas públicas e particulares de Porto Alegre, Rio Grande do Sul, Brasil. Os dados quantitativos foram analisados por meio de descrição de frequências e da análise de associação entre variáveis. Para os dados qualitativos, utilizou-se o método de análise de conteúdo na modalidade temática. Os resultados mostram que apenas 5\% dos adolescentes solicitaram ajuda para problemas decorrentes de violência e, quando o fizeram, procuraram principalmente amigos e familiares. Os profissionais de saúde foram pouco citados pelos jovens como fonte de ajuda. Destaca-se a necessidade de questionar as implicações do sistema de atenção à saúde na prevenção da violência e promoção da saúde dos adolescentes com vistas à adoção de relacionamentos saudáveis.

Violência Contra a Mulher; Saúde do Adolescente; Prevenção Primária; Promoção da Saúde 


\section{Introdução}

Neste estudo, que integra o projeto de base Violência entre Namorados Adolescentes: Um Estudo em Dez Capitais (coordenado pelo Centro Latino-Americano de Estudos de Violência e Saúde Jorge Careli, Escola Nacional de Saúde Pública Sergio Arouca, Fundação Oswaldo Cruz - ENSP/ Fiocruz), adota-se a definição de violência nas relações afetivo-sexuais entre adolescentes como sendo "qualquer comportamento que seja prejudicial ao desenvolvimento e à saúde da(o) parceira(o), comprometendo sua integridade física, psicológica ou sexual" 1 (p. 8).

A violência entre adolescentes em seus relacionamentos íntimos é um tema recente na literatura científica. Até meados da década de 1980, a comunidade científica manteve seu foco nos relacionamentos entre adultos ou jovens adultos, buscando conhecer sua dinâmica para propor estratégias de prevenção. Somente a partir da década de 1990, houve aumento desse interesse, e alguns estudos foram realizados com o objetivo de compreender e atuar na prevenção da violência existente nas relações afetivo-sexuais de adolescentes, sobretudo dos escolares 2 .

Essa carência de pesquisas sobre a temática da violência entre namorados adolescentes pode ser justificada pela ideia de que "namoro não é lugar de violência" 3 (p. 142). Entre as hipóteses para tal representação social dominante, podese citar a percepção de que a violência de gênero situa-se apenas nos relacionamentos mais estáveis ou mais estruturados, situação que exclui as relações de namoro e de "ficar", comuns entre os adolescentes 3 .

Estudos indicam que a violência de gênero afeta negativamente a saúde sexual e reprodutiva das mulheres e também dos homens, principalmente pelo aumento de situações de exposição a riscos de contaminação e disseminação de doenças sexualmente transmissíveis (DST) e AIDS, que estão presentes em contextos de relações violentas. Meninas adolescentes que vivenciam situações de violência de gênero muitas vezes têm maior dificuldade de acesso a serviços de saúde, aos meios de prevenção de gravidez e menor possibilidade de negociar o uso de preservativos com o parceiro 4,5 .

Adolescentes envolvidos em violência afetivo-sexual - vítimas ou perpetradores - geralmente não procuram ajuda profissional. Diante desse fato, a elaboração de medidas de prevenção e aquelas que auxiliem a identificação precoce do problema são desafios para qualificar a ação sistêmica sobre esses eventos. Entretanto, constatam-se dificuldades na implementação de programas de prevenção e intervenção, entre os quais: o estigma associado ao ato de buscar ajuda para problemas pessoais; a preocupação dos adolescentes com a privacidade e a proteção de suas relações afetivas; o apreço pela autossuficiência e a falta de informação dos adolescentes para avaliar a qualidade dos seus relacionamentos afetivos 6 .

Diante desse contexto, buscou-se analisar a busca por serviços de atenção e a rede de apoio referida pelos adolescentes estudantes do Ensino Médio das redes pública e privada de Porto Alegre (Rio Grande do Sul, Brasil) no enfrentamento das situações de violência nas relações afetivosexuais e as inter-relações com o setor saúde.

\section{Metodologia}

A metodologia deste estudo triangula métodos e técnicas quantitativas e qualitativas, buscandose apreender diferentes dimensões do problema investigado, compreender seus significados mais profundos e as relações sociais que os propiciam, de forma complementar 7 .

A população do estudo foi composta por estudantes do segundo ano do Ensino Médio de escolas públicas estaduais e particulares de Porto Alegre. A amostra foi dimensionada para se obterem estimativas de proporção, com erro absoluto de 0,10 , nível de $95 \%$ de confiança e proporção (P) da ocorrência de vitimização entre namorados igual a 70\%. Utilizou-se amostragem conglomerada multiestágio, com seleção em duas etapas: (1) escolha das escolas, com probabilidade de seleção proporcional à quantidade de estudantes de segundo ano em cada estrato; (2) seleção de uma turma aleatoriamente na escola selecionada para a aplicação do questionário com todos os estudantes. O cálculo amostral previu a participação de 319 adolescentes, sendo 160 do ensino público e 159 do ensino privado. Desse total, foram excluídos 32 participantes, de acordo com os seguintes critérios: não ter informado a idade e nunca ter "ficado" ou namorado. Assim, a amostra analisada foi composta por 283 adolescentes de 11 escolas, sendo 157 estudantes do ensino público (seis escolas) e 126 do ensino privado (cinco escolas).

A etapa de coleta dos dados quantitativos e qualitativos, em nível nacional, foi realizada no ano de 2008.

Os dados quantitativos foram obtidos por meio de um questionário aplicado aos estudantes, de forma anônima, em sala de aula. O instrumento foi composto por diversas questões, entre elas: identificação do adolescente, relacionamento familiar e com pares, uso de substâncias, busca de apoio social, crenças sobre os 
usos de violência entre namorados e uma escala para avaliação sobre namoros e violência. Neste estudo, porém, optou-se por analisar apenas as questões que tratavam da busca por ajuda para problemas decorrentes de violência no namoro.

A violência existente nas relações afetivosexuais entre adolescentes foi aferida pela escala Conflict in Adolescent Dating Relationships Inventory (CADRI). A busca por ajuda foi aferida por meio de questões que investigavam se o adolescente já havia precisado procurar ajuda profissional por causa de algum tipo de violência causada por pessoas com quem já havia namorado ou "ficado", que tipo de ajuda procurou e como foi a ajuda recebida; questionou-se, também, quem o jovem considera mais indicado para ajudá-lo e ao parceiro nessas situações.

Com o auxílio do software SPSS versão 18.0 (SPSS Inc., Chicago, Estados Unidos), os dados quantitativos foram analisados por meio de descrição da frequência absoluta e da relativa, que possibilitaram a exploração do material obtido. A análise de associação entre as variáveis categóricas por sexo e rede de ensino foi realizada utilizando-se o teste qui-quadrado de Pearson (valor de $\mathrm{p}<0,05$ indicaram associações estatisticamente significativas).

Os dados qualitativos foram gerados por meio de entrevistas em profundidade e de grupos focais. Foram realizadas quatro entrevistas individuais: uma com menina de escola particular, uma com menino de escola particular, uma com menina de escola pública e uma com menino de escola pública. Formaram-se seis grupos focais, três em escolas particulares e três em escolas públicas, com a seguinte composição: um grupo focal com meninos, um grupo focal com meninas e um grupo focal misto; participaram de cada grupo de seis a nove adolescentes. As entrevistas e as discussões dos grupos focais foram transcritas na íntegra.

Para a análise dos dados qualitativos empregou-se o método de Análise de Conteúdo, seguindo-se a técnica de Análise Temática proposta por Minayo ${ }^{8}$, com base em Bardin ${ }^{9}$, realizada com o auxílio do software NVivo versão 9.2 (QRS International Pty., Doncaster, Austrália). A análise temática, neste estudo, foi utilizada para buscar elementos reflexivos sobre o que os adolescentes pensam não só da relação violência e saúde, mas também das estratégias de prevenção da violência. Desse modo, foi elaborada uma categoria de análise "busca de ajuda no enfrentamento da violência nos relacionamentos afetivo-sexuais entre adolescentes", com base na qual foram elaboradas subcategorias: "apoio dos amigos", "apoio da família", "apoio da escola", "apoio da mídia” e "apoio dos profissionais de saúde”.
O estudo de base foi submetido ao Comitê de Ética em Pesquisa da ENSP/Fiocruz, sendo aprovado sob o número 07/08-CAAE: 0011.0.031.00008, em 11 de março de 2008. Os adolescentes foram convidados a participar da pesquisa, tendo garantido o direito de recusarem-se. Ressalta-se que houve boa aceitação dos adolescentes às diferentes modalidades metodológicas da pesquisa. Os dados locais foram coletados com a autorização da Secretaria de Educação do Estado do Rio Grande do Sul e das direções das escolas participantes. Cada participante assinou um termo de Consentimento Livre e Esclarecido, o qual foi igualmente assinado pelos diretores das escolas e pelos pais dos estudantes, para permitir o acesso às escolas e a participação dos jovens na pesquisa.

\section{Resultados e discussão}

Entre os adolescentes que participaram do estudo, apenas $5 \%$ afirmaram já ter solicitado ajuda profissional por causa de algum tipo de violência perpetrada por pessoa que namorou ou com quem "ficou" (3,9\% por problemas emocionais decorrentes dessas violências e $1,1 \%$ por consequências físicas associadas). Não houve diferenças significativas em relação aos sexos e às redes de ensino.

A análise da pesquisa nacional também mostrou que, em todas as regiões do país, raramente os adolescentes procuram ajuda em situações de violência nas relações afetivas. Apenas 3,5\% afirmaram já ter solicitado apoio profissional em decorrência de algum tipo de violência causada por pessoa que namorou ou com quem "ficou" e, entre esses, a procura foi motivada, principalmente, por problemas emocionais 10 .

Aos adolescentes que afirmaram ter procurado apoio foi perguntado a quem recorreram nesses casos. Constatou-se que, em primeiro lugar, são procurados os amigos (51,5\%) e, em segundo, os familiares (36,7\%). Profissionais de saúde foram citados por $12,1 \%$ dos adolescentes que buscaram ajuda.

No conjunto das dez capitais pesquisadas no estudo nacional, os amigos também apareceram em primeiro lugar $(45,9 \%)$ e os familiares, em segundo (24,2\%), na busca de ajuda decorrente de violência no namoro. Foram citados, com menor frequência, profissionais religiosos $(3,6 \%)$, profissionais de saúde (3,3\%) e professores (2,6\%) 10.

Os adolescentes que buscaram apoio também foram questionados sobre a qualidade da ajuda que receberam, e 71,5\% deles classificaram como excelente e boa, enquanto $28,5 \%$ a consideraram regular e ruim, não se constatando di- 
ferenças significativas em relação aos itens sexo e redes de ensino.

Perguntando-se, de forma hipotética, a todos os adolescentes participantes, quem seria a pessoa mais indicada para ajudá-los em caso de violência nessas relações, observou-se que os familiares são os primeiros a serem lembrados $(35,4 \%)$, seguidos pelos amigos $(28,2 \%)$. Os profissionais de saúde foram citados por $10,7 \%$ dos adolescentes; os educadores, por 1,1\%; os religiosos, por $0,4 \%$.

No estudo nacional foram encontrados resultados semelhantes. Os familiares $(46 \%)$ e os amigos $(22,1 \%)$ foram os mais citados. Em seguida, foram mencionados os profissionais de saúde $(13,4 \%)$ e os educadores e religiosos (1,5\% cada). A ajuda recebida foi considerada boa ou excelente por $90 \%$ dos adolescentes, indicando que obtiveram o suporte esperado 10 .

Observa-se uma contradição na busca de ajuda para as situações de violência nos relacionamentos. Enquanto os familiares são, supostamente, os mais indicados para ajudar os adolescentes, são os amigos a fonte de apoio efetivamente procurada nessas situações. O mesmo ocorre com a ajuda dos profissionais de saúde, que são indicados por $10,7 \%$ dos adolescentes para apoiá-los nas situações de violência, mas foram procurados por apenas $3,3 \%$ dos jovens. Esses resultados podem ser decorrentes da dificuldade de os adolescentes obterem suporte por parte da família e dos serviços de saúde.

Neste estudo, observaram-se diferenças por sexo sobre a concepção que os adolescentes têm de quais pessoas seriam as mais indicadas para ajudar. As meninas citaram mais os profissionais de saúde $(13,4 \%)$ do que os meninos (6,5\%). Já os meninos $(39,8 \%)$ citaram mais os amigos como sendo as pessoas mais indicadas para dar apoio nos casos de violências do que as meninas (20,9\%).

A diferença entre gêneros nas opções de apoio nessas situações também foi encontrada em um estudo baseado na fala de 4.634 jovens de três capitais brasileiras (Porto Alegre, Rio de Janeiro e Salvador) sobre situações de coerção sexual. Mais da metade dos jovens relatou o evento para alguém. Porém, enquanto, entre as meninas, os interlocutores mais procurados foram os parentes, entre os meninos, os mais procurados foram os amigos 11 .

O fato de os profissionais de saúde serem mais citados pelas meninas pode se dever às diferenças de comportamentos e representações entre os gêneros em relação à saúde e suas práticas. De maneira geral, os homens procuram menos os serviços de saúde do que as mulheres, sobretudo para situações de prevenção 12 .
Estudos sobre a utilização dos serviços de saúde por adolescentes identificaram que a maior procura por esses serviços é do sexo feminino, ao passo que os meninos dificilmente buscam atendimento 13,14 . As meninas apresentam maior chance de autoavaliarem seu estado de saúde como ruim ou muito ruim e de demandarem serviços de saúde, em comparação com os meninos 15. A maior utilização dos serviços pelas meninas pode indicar maior preocupação e cuidados com a saúde pela população feminina no grupo adolescente, como é observado para a faixa etária adulta 16. No entanto, sabe-se que os eventos relacionados à saúde sexual e reprodutiva das mulheres demandam e induzem a busca mais precoce de serviços, além da oferta programática ser centrada em etapas da vida das mulheres, que se sustentam na gestação e em cuidados materno-infantis.

Em relação às diferenças entre as redes pública e privada de ensino, foi encontrada diferença quanto à menção dos familiares como fonte de ajuda. Os estudantes do ensino público $(41,6 \%)$ citaram mais os familiares do que os do ensino privado $(27,8 \%)$. Talvez porque a população pertencente a classes economicamente desfavorecidas tenha menor acesso a serviços de saúde, mesmo tendo maiores necessidades de cuidados 17. Assim sendo, os recursos para buscar ajuda, muitas vezes, limitam-se à rede sociofamilar.

Em estudo transversal, realizado nas escolas do Município de Niterói (Rio de Janeiro), que descreveu a relação de adolescentes, entre 12 e 17 anos, com os serviços de saúde, os autores identificaram que o nível socioeconômico, representado pelo tipo de escola (pública ou privada), mostrou-se associado a todos os indicadores utilizados na avaliação. Os alunos das escolas públicas tinham maior chance do que os das escolas privadas de avaliarem seu estado de saúde como regular ou ruim e chance menor de expressarem a necessidade sentida positivamente, demandarem serviços de saúde, obterem acesso aos serviços procurados e manterem-se fiéis aos serviços utilizados 15 .

Com base na análise das entrevistas e grupos focais com os adolescentes foi possível formular a categoria de análise temática "busca de ajuda no enfrentamento da violência nos relacionamentos afetivo-sexuais entre adolescentes", a qual é apresentada e discutida a seguir a partir de subcategorias, extraídas das próprias falas.

\section{Apoio dos amigos}

Os adolescentes disseram que os amigos são as pessoas mais procuradas para dividir experiên- 
cias e ouvir opiniões sobre as dificuldades nos relacionamentos afetivo-sexuais. Essa preferência ocorre pelo fato de os amigos estarem vivenciando situações semelhantes decorrentes da fase da vida em que se encontram. Assim sendo, os adolescentes se sentem mais à vontade para falar de seus relacionamentos com os amigos do que com os pais, como se verifica nos trechos a seguir:

"Eu tenho um amigo meu, ele é realmente muito meu amigo, que é mais velho, e a gente conversa sobre isso" (menina, escola particular).

"A primeira pessoa que a gente conversa écom os amigos, falar com os pais é mais estranho!" (menino, escola particular).

Uma pesquisa realizada em São Paulo, com 383 adolescentes de 15 a 19 anos de idade, cujo objetivo foi identificar com quem os jovens compartilhavam informações e diálogos sobre sexualidade, apontou os amigos como os indivíduos mais procurados para tratar dessas questões 18 . Alguns autores afirmam que os amigos parecem ser mais influentes do que os pais na formação de padrões de comportamento aceitáveis no namoro durante a adolescência. Além disso, os adolescentes são mais propensos a serem vítimas ou perpetradores de violência quando seus amigos estão em uma relação de namoro violenta 19.

No estudo nacional desta pesquisa também foi identificado que os amigos são as pessoas com quem os adolescentes contam para desabafar e trocar informações. A preferência pelos amigos, na maioria dos casos, ocorre pela falta de espaço para diálogo nas famílias. Os jovens consideram que certos temas são tabus no ambiente familiar e que determinados comportamentos são considerados proibidos e errados pelos pais. Também existe a crença de que a diferença geracional impede os progenitores de compreenderem seus filhos adolescentes 10 .

Os amigos são, portanto, a primeira escolha dos adolescentes; estes destacam facilidades nos processos comunicativos geracionais e ausência do compromisso do parentesco na análise das situações conflitantes. Outro argumento, também, é a inexistência de ajuda de outra natureza que seja próxima e acessível aos jovens e, por vezes, mais adequada a situações extremas de conflito. Cita-se, nesses casos, a ajuda profissional como alternativa não só qualificada, mas necessária.

\section{Apoio da família}

Os adolescentes consideram os familiares como as pessoas mais indicadas para ajudá-los em caso de violência nas relações afetivo-sexuais. No entanto, muitos disseram ter dificuldades de comunicação com os pais.
Alguns dos jovens entrevistados citaram o papel desempenhado pelos irmãos mais velhos como fonte de apoio e informação.

"O que eu não posso comentar com minha mãe eu começo a comentar com minha irmã" (menina, escola pública).

"Então, o pai não precisa fazer isso [conversar sobre sexualidade], sabe? Meus irmãos fazem muito bem isso, sabe?" (menino, escola particular).

Esses achados são similares aos de outros estudos que revelam que a maioria dos adolescentes envolvidos em relações de namoro violentas não procura ajuda, e, quando o faz, amigos e familiares são as fontes mais comuns de busca de apoio em detrimento da procura por profissionais. Tanto vítimas quanto perpetradores identificam os amigos como fonte de ajuda na maioria das vezes, evidenciando a utilização dos pares como confidentes e conselheiros 6 .

Por outro lado, os adolescentes reconhecem a importância do diálogo aberto com os pais para instrução e formação. Afirmam que a família deveria ser a principal fonte de ajuda para os adolescentes no que se refere a problemas nos relacionamentos, incluindo as situações de violência.

"É, eu acho que quando tu realmente precisa é pra eles que tu corre. [...] É claro que tu não vai contar tudo pros teus pais, mas ali eles tão, tão sabendo, tipo, tá segura" (menina, escola pública).

"Amigo a gente conversa mais em particular, com quem a gente confia. Faz mais uma pesquisa assim, mas, se for um 'bagulho' grave, daí é mais com os pais, que vão poder tomar uma atitude por você" (menino, escola particular).

Pesquisadores ressaltam a comunicação com a mãe ou outros familiares sobre sexualidade como fator-chave para os comportamentos, os valores e as atitudes dos adolescentes nas relações afetivo-sexuais. Jovens que têm um relacionamento mais aberto com suas mães tendem a estabelecer maiores reflexões sobre seus relacionamentos com namorados 20. Contudo, ainda existe dificuldade de os familiares conversarem abertamente com os adolescentes sobre sexualidade e relacionamentos amorosos. Comumente, quando ocorre conversa, as abordagens dos pais se reduzem à prevenção de DST e de gravidez indesejada, principalmente para as meninas. As dificuldades muitas vezes são em mão dupla, ao mesmo tempo em que os pais não sabem como falar com seus filhos sobre isso, os filhos também não gostam de falar com os pais, às vezes por vergonha ou medo. Além disso, também se observam diferenças no tratamento de meninas e meninos. Ainda persistem atitudes que demonstram uma dupla moral no plano da sexualidade, culpabilizante e repressora para as meninas. 
"Por exemplo, vamos falar dos pais assim, falar de sexo com os pais é uma coisa estranha assim, né?" (menino, escola particular).

"Eu acho com os pais mais difícil [falar sobre sexualidade]. Pra guri é mais fácil, essas coisas de usar camisinha; pra guria é mais difícil" (menina, escola particular).

Observa-se que a sexualidade, ainda considerada tabu na sociedade, provoca incômodos que afetam profundamente as relações entre adolescentes e adultos, sejam pais, sejam professores 10. Muitas vezes, a família se exime de tratar desse assunto com os jovens, deixando essa "tarefa" exclusivamente para a escola. Entretanto, se a instituição escolar não reconhece como sua essa responsabilidade, os adolescentes ficam desamparados no que se refere à educação sexual e à oportunidade de discussões sobre seus relacionamentos.

O estudo nacional identificou que existe uma grande lacuna entre o que é idealizado pelos adolescentes e o que acontece na vida real. Ao mesmo tempo em que os adolescentes têm uma expectativa de compreensão e apoio dos pais experimentam, por outro lado, um sentimento de revolta contra o controle excessivo que estes exercem sobre seus namoros, principalmente em relação às meninas 10 .

Mesmo com essas limitações, a família exerce influência predominante. Observou-se que $67,3 \%$ dos adolescentes afirmaram ter tido algum tipo de orientação sobre sexualidade fora da escola. As meninas $(71,1 \%)$ dizem ter recebido orientação com mais frequência do que os meninos $(61,1 \%)$. A maior parte das orientações aos jovens foi dada pelas famílias $(46,6 \%)$ e pelos amigos (33,2\%). Meios de comunicação, como televisão (23\%) e revistas (15,5\%), também foram citados.

Pode-se argumentar que, no enfrentamento da violência, estratégias de educação voltadas para a sexualidade dos adolescentes, as quais considerem as redes de relações e subjetividades destes, são mais efetivas e capazes de produzirem influências marcantes nas suas condutas e atitudes. Nesse sentido, considera-se que atividades envolvendo o adolescente e sua família, desenvolvidas com o auxílio da escola e dos serviços de saúde, podem facilitar a superação das dificuldades de comunicação e propiciar uma discussão mais aberta sobre assuntos considerados de difícil abordagem, como é o caso da sexualidade.

\section{Apoio da escola}

Quanto ao papel da escola, constatou-se que $61,8 \%$ dos adolescentes tiveram alguma palestra ou aula sobre educação sexual na escola no ano anterior à pesquisa, ainda que esse assunto tenha sido abordado com pouca frequência $(58,2 \%$ dos adolescentes informaram terem tido aula ou palestra sobre educação sexual menos de uma vez por mês). Na maioria dos casos $(44,5 \%)$, quem ministrou esse conteúdo aos estudantes foi uma pessoa de fora da escola (convidada). Não se constatou diferença entra as redes de ensino.

Em relação a essas informações recebidas, os adolescentes fizeram algumas críticas às abordagens, que nem sempre conseguem atingir o público-alvo, mostrando-se ineficazes na comunicação. Citaram, porém, alguns professores que têm posturas mais "abertas" e que, dessa forma, conseguem estabelecer empatia com os estudantes.

"Depende da pessoa, porque tu vê aquela professora que estava ali, ela não conversa sobre isso, ela vai lá, dá a matéria e pronto. Agora, no ano passado a gente tinha professores mais jovens que falavam sobre isso e brincavam, não sei o quê. Até teve uma vez, numa gincana, que uma professora estava sorteando pirulito e ela cantava:- Quem é que tem camisinha no bolso? Vai ganhar pirulito. Assim, brincadeiras interessantes, né?" (menina, escola pública).

Percebe-se que a escola apresenta resistência em tomar para si a tarefa de falar sobre sexualidade com os adolescentes quando se trata de educação sexual, dando preferência a convidados externos, em formato de palestras isoladas. Muitas vezes, as abordagens se limitam a aspectos biológicos do aparelho reprodutor, métodos contraceptivos e DST, sem criar oportunidade para que os adolescentes possam conversar sobre afetividades nessas relações, por exemplo.

A escola é reconhecida pelos adolescentes como instituição potencialmente apropriada para orientá-los sobre assuntos pautados nos relacionamentos afetivo-sexuais. Desse modo, os estudantes sugerem que o ambiente escolar promova espaços permanentes para esclarecimentos das dúvidas.

"Eu acho que devia ter aula sobre isso no colégio" (menina, escola particular).

"Acho que, no colégio, [...] tinha que ter como uma matéria, entendeu?" (menina, escola pública).

Para os adolescentes participantes do estudo nacional, a escola também foi considerada importante fonte de informações sobre assuntos típicos do período da adolescência - o namoro e a sexualidade. No entanto, a maioria deles considera que a escola dá pouca atenção aos aspectos da vida emocional dos adolescentes e que deveria abordar mais os temas que envolvem o cotidiano da juventude 10 
A esse respeito, as pesquisadoras consideram que a escola poderia ter papel mais atuante na problematização da violência nos relacionamentos entre os adolescentes, especialmente por constituir um espaço de socialização, onde os jovens passam boa parte do seu tempo, desempenhando papel fundamental na formação deles. Entretanto, muitas vezes a escola se mostra despreparada para enfrentar os desafios citados pelos adolescentes e para desenvolver intervenções pedagógicas que focalizem os valores de educação para a vida 10 .

Assis et al. 21 apontam a valorização da escola como importante promotora da cultura da paz, minimizadora da vulnerabilidade a de diversas formas de violências e, ainda, instrumento essencial para a promoção de cidadania e inclusão social. Os autores destacam a importância do desenvolvimento de programas de forma integrada, ampliando as possibilidades e atuando nos âmbitos individual, familiar, comunitário e social. Ainda segundo os autores, os caminhos para o enfrentamento das violências devem ser construídos sob a ótica da valorização da integração comunitária, que não elimina os conflitos, mas contribui para o desenvolvimento de comportamentos mais tolerantes, repercutindo positivamente no próprio desempenho escolar.

Nessa perspectiva, considera-se que a parceria entre escolas e serviços de saúde, especialmente os de atenção básica, pode ser uma boa estratégia para o desenvolvimento de ações de informação, esclarecimento e apoio aos adolescentes no que se refere aos seus relacionamentos afetivos e à prevenção de situações de violência.

\section{Apoio da mídia}

Também foi questionado aos adolescentes como eles avaliavam o papel da mídia para a divulgação de informações. Alguns disseram que as campanhas na televisão ajudam, mas outros afirmaram que elas não atingem os adolescentes por se voltarem ao público adulto ou porque, simplesmente, os adolescentes não prestam atenção.

"Atingem uma pequena parte [...] Eu acho que [o adolescente] não dá bola" (menino, escola particular).

"É legal, mas eu acho que não funciona. Não é, tipo, uma propaganda que diz que pra usar camisinha, que tu vai usar" (menina, escola pública).

Os programas de TV foram criticados por fugirem da realidade dos adolescentes. Porém, os entrevistados afirmam que programas com abordagens diferenciadas poderiam ser eficazes para ajudar os jovens a esclarecerem suas dúvidas.

"[os programas de TV] tão mais preocupados com o que vai aparecer assim, de errado, do que informar a pessoa. [...] Tá faltando um programa num horário mais acessível" (menino, escola particular).

Njaine 22 afirma que, apesar das contradições da produção midiática em relação à sua função pública de informar, a televisão constitui uma fonte de informação importante para os adolescentes. Contudo, para qualificar as interações entre os adolescentes e a mídia, é preciso desnaturalizar algumas noções de violência veiculadas por esta e construir espaços coletivos e democráticos para os jovens se expressarem.

É necessário destacar, também, o papel desempenhado pela internet como fonte de informação para os adolescentes. A possibilidade de pesquisar informações em uma infinidade de sítios, podendo manter-se anônimo para esclarecer dúvidas, pode ser vista como importante estratégia de auxílio a esse grupo populacional específico, que consome intensamente esse tipo de cultura comunicacional.

"Internet também. É, mas tem que olhar em mais de um site e ir comparando" (menina, escola particular).

Vale lembrar que a Internet e suas ferramentas são utilizadas como um modo de os adolescentes se relacionarem afetivamente. As conexões virtuais ampliam a possibilidade de experimentação das relações entre os jovens. Do mesmo modo, esse espaço pode ser empregado para controlar o outro e, consequentemente, para praticar violência, como, por exemplo, a difamação do(a) parceiro(a) em sites de relacionamento 23 .

A pesquisa nacional identificou que a mídia é citada pelos adolescentes como um meio que possibilita atuar na prevenção da violência no namoro. Seja pela veiculação de conteúdos importantes e pela interação que permite, seja pela polêmica gerada por alguns conteúdos, instigando críticas e debates entre os jovens, a mídia desempenha papel especial de apoio aos jovens 10 .

Njaine 24 declara que, como fonte de informação para vários temas de interesse dos adolescentes, os meios de comunicação podem promover novas interações, novos sentidos sobre a realidade, tendo impacto direto e indireto na socialização desse grupo. Pensando na prevenção da violência na mídia, a autora aponta diversas ações que poderiam ser realizadas no âmbito da saúde pública, dentre as quais: utilizar as mídias para criar dinâmicas de discussão com os adolescentes sobre a questão da violência e demonstrar-lhes atitudes morais, emocionais e intelectuais, por meio do diálogo, as quais sejam capazes de solucionar conflitos. 


\section{Apoio dos profissionais de saúde}

Mesmo sendo citados nos questionários, nas entrevistas e grupos focais, os serviços de saúde foram pouco mencionados pelos adolescentes. Estes relatam não procurar os profissionais da saúde para obter ajuda quando há problemas nos relacionamentos afetivo-sexuais.

"Têm psicólogos em posto de saúde [...], mas não sei. Mesmo assim, não tem procura né, porque falta alguém incentivar para essa pessoa ir" (menina, escola particular).

$\mathrm{O}$ estudo nacional constatou que os adolescentes raramente procuram os serviços de saúde, a não ser para solicitação de atestados ou quando há interesse por alguma palestra; neste último caso, a maioria é de meninas para informações sobre gravidez. Os meninos procuram os serviços para pegar preservativos. Para os adolescentes, os profissionais de saúde, geralmente, estão associados a doenças e à necessidade de consultas médicas. Algumas vezes, os profissionais são lembrados quando sua função está associada à escola, como é o caso dos psicólogos 10.

Outros estudos revelam que a procura pelos serviços de saúde tem caráter mais curativo do que preventivo, indicando que o motivo pelo qual o adolescente procura o serviço de saúde não vai além dos problemas clínicos 14,16. É possível que esse padrão de demanda esteja relacionado à inexistência de oferta e de divulgação de ações de promoção da saúde nos serviços acessíveis e comprometidos com as necessidades desse grupo.

Em uma investigação com adolescentes de Porto Alegre, voltada a compreender a morbidade por causas externas (acidentes e violências) entre esse grupo populacional, observou-se que, em raros momentos, os jovens mencionaram relações com os serviços de saúde. Além disso, não identificaram os serviços como locais de referência para agravos decorrentes de violências 25 .

Apesar desse achado, segundo Njaine et al. 10, é função do setor saúde acolher, escutar, atender os adolescentes e jovens e orientá-los quanto à sexualidade e quanto às violências que podem ocorrer nas relações afetivo-sexuais. Contudo, observa-se que mesmo as altas prevalências de mulheres adultas em situação de violência nas relações íntimas ainda têm pouca visibilidade nos serviços de saúde. É importante ressaltar que, embora adolescentes do sexo feminino e, mais ainda, do sexo masculino procurem pouco os serviços de saúde, eles afirmaram o desejo de ter esse espaço para buscar informações e receber apoio.

"Na minha opinião, acho que funciona um ginecologista ou um psicólogo que é uma pessoa neutra. Você pode falar o que quiser para ela" (menino, escola particular).

"Eu acho que deveria ser [...] alguém que tenha alguma especialidade [...] informação pra passar pra juventude" (menino, escola particular).

Nesse sentido, é necessário tencionar a atuação do setor saúde na prevenção das violências e em particular, nos relacionamentos afetivo-sexuais entre adolescentes, especialmente do ponto de vista da promoção da saúde. Considera-se que a atenção qualificada é essencial para reduzir a frequência de violência entre os jovens nessa faixa etária. A profilaxia de danos decorrentes da violência é igualmente dever do sistema organizado de saúde. Assim sendo, as intervenções estão relacionadas também aos direitos individuais e de cidadania.

\section{Considerações finais}

Ao analisarem-se as falas e as demandas dos adolescentes deste estudo, atentou-se para a compreensão dos diferentes aspectos dos seus cotidianos e contextos, a fim de conhecer as situações de vulnerabilidade e de proteção possíveis em face do fenômeno da violência. Evidencia-se, portanto, a necessidade de intervenção precoce e busca ativa dessa população, promovendo o acesso e a acessibilidade dos adolescentes aos serviços de saúde, nos quais sejam construídos espaços de diálogo aberto e apoio. Considera-se que esses serviços, em conjunto com a escola, famílias e comunidade, têm potencial para elaborar projetos de educação que combatam a banalização e a naturalização da violência nas relações afetivo-sexuais entre os adolescentes, que ocorre de forma diferente, mas bilateral, entre meninas e meninos. Em espaços de acolhimento e reflexão, pode-se colaborar também para evitar a reprodução de formas tradicionais de hierarquia e desigualdades entre os sexos, as quais produzem e legitimam muitas formas de violência de gênero.

Considera-se necessário que o setor saúde atue de forma mais ativa na prevenção das violências e na promoção de atitudes e ações que influenciem nas relações afetivo-sexuais dos adolescentes, envolvendo meninas e meninos nessas abordagens. Para a promoção da saúde, é fundamental estimular comportamentos de procura de ajuda entre jovens envolvidos em violência nas relações de namoro.

Aponta-se o desafio de pensar sobre a responsabilização e o comprometimento do cuidado, a fim de potencializar as ações de saúde na visibilização e enfrentamento das situações de violência. Esse intento representa um desafio ao 
exercício de ações de saúde capazes de assumir o que vai além da oferta básica da saúde de pro- gramas instituídos e ofertados à população e a grupos específicos.

\section{Resumen}

Se analizó la red de apoyo informada por los adolescentes a la hora de enfrentarse a las situaciones de violencia en las relaciones afectivo-sexuales. Se utilizó un enfoque cuantitativo para la encuesta epidemiológica, y cualitativo para los datos de las entrevistas y grupos focales. La muestra estaba compuesta por 283 adolescentes de 15 a 19 años de edad, estudiantes del 2 o año de enseñanza media de escuelas públicas y privadas de Porto Alegre, Rio Grande do Sul, Brasil. Los datos cuantitativos se analizaron a través de la descripción de frecuencias y del análisis de asociación entre variables. Para los datos cualitativos se utilizó el método de análisis de contenido en la modalidad temática. Los resultados muestran que solamente un 5\% de los adolescentes solicitaron ayuda para problemas derivados de violencia y, cuando lo hicieron, buscaron principalmente amigos y familiares. Los profesionales de salud fueron poco citados por los adolescentes como fuente de ayuda. Se destaca la necesidad de cuestionar las implicaciones del sistema de atención a la salud en la prevención de la violencia y promoción de la salud de los adolescentes con vistas a la adopción de relaciones saludables.

Violencia Contra la Mujer; Saúde del Adolescente; Prevención Primária; Promoción de la Salud

\section{Colaboradores}

J. S. F. Soares contribuiu com a concepção, projeto e redação do artigo. M. J. M. Lopes contribuiu com a redação do artigo. K. Njaine contribuiu com a revisão crítica relevante do conteúdo intelectual.

\section{Agradecimentos}

À equipe de pesquisadores(as) do Centro de Estudos de Violência e Saúde Jorge Careli (CLAVES), da Escola Nacional de Saúde Pública Sergio Arouca da Fundação Oswaldo Cruz (ENSP/Fiocruz). À equipe de pesquisadoras do Grupo de Estudos em Saúde Coletiva (GESC), da Escola de Enfermagem da Universidade Federal do Rio Grande do Sul (UFRGS).

Este artigo é originário da Dissertação de Mestrado Violências nas Relações Afetivo-Sexuais entre Adolescentes do Ensino Médio de Escolas Públicas e Privadas de Porto Alegre: Prevalência e Redes de Apoio (Escola de Enfermagem/UFRGS; 2012) de J. S. F. Soares, cujo estudo integra um projeto de base, intitulado Violência entre Namorados Adolescentes: um Estudo em Dez Capitais Brasileiras, coordenado por pesquisadoras do CLAVES/ ENSP/Fiocruz. 


\section{Referências}

1. Lavoie F, Robitaille L, Hébert M. Teen dating relationships and aggression: an exploratory study. Violence Against Women 2000; 6:6-36.

2. Cornelius TL, Resseguie N. Primary and secondary prevention programs for dating violence: a review of the literature. Aggress Violent Behav 2007; 12:364-75.

3. Gomes R. Invisibilidade da violência nas relações afetivo-sexuais. In: Minayo MCS, Assis SG, Njaine $\mathrm{K}$, organizadoras. Amor e violência: um paradoxo das relações de namoro e do 'ficar' entre jovens brasileiros. Rio de Janeiro: Editora Fiocruz; 2011. p. 141-51.

4. Ruzany MH, Taquette SR, Oliveira RG, Meirelles $\mathrm{ZV}$, Ricardo IB. A violência nas relações afetivas dificulta a prevenção de DST/AIDS? J Pediatr (Rio J.) 2003; 79:349-54

5. Taquette SR, Ruzany MH, Meirelles ZV, Ricardo IB. Relacionamento violento na adolescência e risco de DST/AIDS. Cad Saúde Pública 2003; 19:1437-44.

6. Ashley OS, Foshee VA. Adolescent help-seeking for dating violence: prevalence, sociodemographic correlates, and sources of help. J Adolesc Health 2005; 36:25-31.

7. Minayo MCS, Assis SG, Souza ER, organizadoras. Avaliação por triangulação de métodos: abordagem de programas sociais. Rio de Janeiro: Editora Fiocruz; 2005.

8. Minayo MCS. O desafio do conhecimento: pesquisa qualitativa em saúde. 10ạ Ed. São Paulo: Editora Hucitec/Rio de Janeiro: ABRASCO; 2007.

9. Bardin L. Análise de conteúdo. Lisboa: Edições 70; 2011.

10. Njaine K, Oliveira QBM, Ribeiro FML, Minayo MCS, Bodstein R. Prevenção da violência nas relações afetivo-sexuais. In: Minayo MCS, Assis SG, Njaine K, organizadoras. Amor e violência: um paradoxo das relações de namoro e do 'ficar' entre jovens brasileiros. Rio de Janeiro: Editora Fiocruz; 2011. p. 183-205.

11. Moraes CL, Cabral CS, Heilborn ML. Magnitude e caracterização de situações de coerção sexual vivenciadas por jovens de três grandes capitais brasileiras: Porto Alegre, Rio de Janeiro e Salvador Cad Saúde Pública 2006; 22:1493-504.

12. Pinheiro RS, Viacava F, Travassos C, Brito AS. Gênero, morbidade, acesso e utilização de serviços de saúde no Brasil. Ciênc Saúde Coletiva 2002; 7:687-707.

13. Ferrari RAP, Thomson Z, Melchior R. Adolescência: ações e percepção dos médicos e enfermeiros do Programa Saúde da Família. Interface Comun Saúde Educ 2008; 12:387-400.
14. Palazzo LS, Béria JU, Tomasi E. Adolescentes que utilizan servicios de atención primaria: ¿Cómo viven? ¿Por qué buscan ayuda y cómo se expresan? Cad Saúde Pública 2003; 19:1655-65.

15. Claro LBL, March C, Mascarenhas MTM, Castro IAB, Rosa MLG. Adolescentes e suas relações com serviços de saúde: estudo transversal em escolares de Niterói, Rio de Janeiro, Brasil. Cad Saúde Pública 2006 ; 22:1565-74.

16. Formigli VLA, Costa MCO, Porto LA. Avaliação de um serviço de atenção integral à saúde do adolescente. Cad Saúde Pública 2000; 16:831-41.

17. Néri M, Soares W. Desigualdade social e saúde no Brasil. Cad Saúde Pública 2002; 18 Suppl:S77-87.

18. Borges ALV, Nichiata LYI, Schor N. Conversando sobre sexo: a rede sociofamiliar como base de promoção da saúde sexual e reprodutiva de adolescentes. Rev Latinoam Enferm 2006; 14:422-7.

19. Arriaga X, Foshee V. Adolescent dating violence: do adolescents follow in their friends', or their parents', footsteps? J Interpers Violence 2004; 19:16284.

20. Romo LF, Lefkowitz ES, Sigman M, Au TK. A longitudinal study of maternal messages about dating and sexuality and their influence on Latino adolescents. J Adolesc Health 2002; 31:59-69.

21. Assis SGD, Deslandes SF, Santos NC. Violência na adolescência: sementes e frutos de uma sociedade desigual. In: Ministério da Saúde, organizador Impacto da violência na saúde dos brasileiros. Brasília: Ministério da Saúde; 2005. p. 79-105. (Série B. Textos Básicos de Saúde).

22. Njaine K. Sentidos da violência ou a violência sem sentido: o olhar dos adolescentes sobre a mídia. Interface Comun Saúde Educ 2006; 10:381-92.

23. Ribeiro FML, Avanci JQ, Carvalho L, Gomes R, Pires TO. Entre o ficar e o namorar: relações afetivosexuais de adolescentes. In: Minayo MCS, Assis SG, Njaine K, organizadoras. Amor e violência: um paradoxo das relações de namoro e do 'ficar' entre jovens brasileiros. Rio de Janeiro: Editora Fiocruz; 2011. p. 55-86.

24. Njaine K. Violência na mídia e saúde. In: Lima CA organizador. Violência faz mal à saúde. Brasília: Ministério da Saúde; 2004. p. 223-31.

25. Cocco M, Lopes MJM. Violência entre jovens: dinâmicas sociais e situações de vulnerabilidade. Rev Gaúch Enferm 2010; 31:151-9.

Recebido em 28/Ago/2012

Versão final reapresentada em 19/Dez/2012

Aprovado em 01/Fev/2013 